\title{
Can the reproductive system of a rare and narrowly endemic plant species explain its high genetic diversity?
}

\author{
Daniele M. Rodrigues' ${ }^{1}$ Caroline Turchetto', Sidia M. Callegari-Jacques ${ }^{2}$ and Loreta B. Freitas ${ }^{1 *}$
}

Received: August 11, 2017

Accepted: October 31, 2017

\begin{abstract}
The reproductive system of flowering plants can be highly variable, affecting their biology, gene flow and genetic variability among populations. Petunia secreta is a rare annual endemic species of Pedra do Segredo, located in the municipality of Caçapava do Sul, state of Rio Grande do Sul, Brazil. Although rare, the species possesses a high level of genetic variability. We investigated the reproductive system of $P$. secreta, including fruit production and seed germinability, in order to determine if its reproductive system can explain its genetic diversity. We sampled five populations and conducted five greenhouse hand-pollination treatments: 1) autonomous apomixis; 2) self-pollination; 3) hand self-pollination; 4) geitonogamy; and 5) cross-pollination. We analysed a total of 40 plants, 468 flowers, and 6,500 seeds. Only autonomous apomixis and self-pollination did not produce fruit. No differences in fruit weight were observed among pollination treatments $(\mathrm{P}>0.05)$. Seeds of two colours were produced, with no differences in germinability. Considering all plants, populations, and treatments, the average germinability was $73 \%$ (range $9 \%$ to $100 \%$ ). These results, along with other previous studies, indicate that the reproductive systems of $P$. secreta, and its large effective population size, can explain its high genetic diversity.
\end{abstract}

Keywords: endogamy, Pampas, Petunia, reproductive success, reproductive system, seed germinability

\section{Introduction}

The genetic structure of a plant species is shaped by gene flow within and between populations. A key factor influencing patterns of seed and pollen dispersal is the species' mode of reproduction (Ghazoul 2005). Physical changes, including habitat degradation or fragmentation, can affect both gene flow and reproduction (Aguilar et al. 2008) by reducing the abundance and density of plant individuals, thus resulting in a decrease in population size and an increase in spatial isolation between populations (Blambert et al. 2016).

Plant reproductive systems vary greatly. At one extreme, obligate cross-fertilization in self-incompatible species requires a mate and a pollen vector. At the other end of the spectrum, obligate self-fertilization in self-compatible species is less dependent on mates and vectors. As a consequence, a species' reproductive system may influence its genetic diversity (Charlesworth 2006). In the context of worldwide biodiversity loss, the management of a threatened plant species requires an understanding of its life history and reproductive system as key factors determining the species' abundance, distribution, genetic diversity, and persistence. Therefore, management efforts to preserve endangered species should build on both ecological and genetic studies.

Here, we investigated the reproductive system of Petunia secreta (Solanaceae), a rare annual herbaceous

\footnotetext{
1 Laboratório de Evolução Molecular, Departamento de Genética, Universidade Federal do Rio Grande do Sul, P. O. Box 15053, 91501-970, Porto Alegre, RS, Brazil

2 Departamento de Estatística, Universidade Federal do Rio Grande do Sul, P. O. Box 15080, 91501-970, Porto Alegre, RS, Brazil

* Corresponding author: loreta.freitas@ufrgs.br
} 
species that is endemic to a small area in the municipality of Caçapava do Sul, Serra do Sudeste, southern Brazil (Fig. 1; Stehmann \& Semir 2005). According to the criteria adopted by the International Union for the Conservation of Nature, $P$. secreta is classified as critically endangered (Turchetto et al. 2016). Despite this, it is not included on the Brazilian red list of plant species. Within the phylogeny of the genus, the species belongs to a clade characterised by long corolla tubes (Reck-Kortmann et al. 2014). It can be subdivided into two different genetic lineages, which correspond to its sites of occurrence (lineage 1, from Pedra do Segredo - see below, and lineage 2, from a roadside location approximately $20 \mathrm{~km}$ away; Turchetto et al. 2016). Based on its pink corolla, Petunia secreta has been described as beepollinated (Stehmann \& Semir 2005). We have confirmed through field experiments conducted at Pedra do Segredo (DM Rodrigues unpubl. res.). Plants from the roadside location possess the same morphological characteristics, suggesting they are also bee-pollinated, but to date, their pollinators have not been investigated. Although P. secreta is a rare and narrow endemic species, which generally grows in small fragmented populations, its genetic variability is high and of ancient origin, especially when compared to other Petunia species. Analyses of nuclear genetic markers confirm that the extant populations of $P$. secreta are descended from a single large and stable founder population (Turchetto et al. 2016).
Here, we address the following questions: (1) what is the reproductive system of $P$. secreta? (2) Is $P$. secreta totally or partially self-incompatible? (3) Do artificial crossings produce seeds, and how viable are these seeds? (4) Are there any constrains to crosses of plants from different populations or evolutionary lineages of $P$. secreta? The obtained results were analysed in the context of the high genetic diversity previously observed in this rare species.

\section{Materials and methods}

\section{Sampling and site of study}

The floral morphology of Petunia secreta Stehmann \& Semir is similar to that of its sister species P. axillaris (Stehmann et al. 2009), and they can only be distinguished by the colour of their corolla (pink in P. secreta; Fig. 2A). The distribution of $P$. secreta is restricted to two isolated locations (Fig. 1) at the northern edge of the Pampas region in Rio Grande do Sul, Brazil. The species was first described at Pedra do Segredo (30³2'S 533' W), a sandstone tower complex set amidst savannah vegetation at an altitude of 300-400 m (RADAMBRASIL Project 2013). At this site, $P$. secreta grows in isolated patches of few individuals. Outside this area, only three groups of individuals have been found,

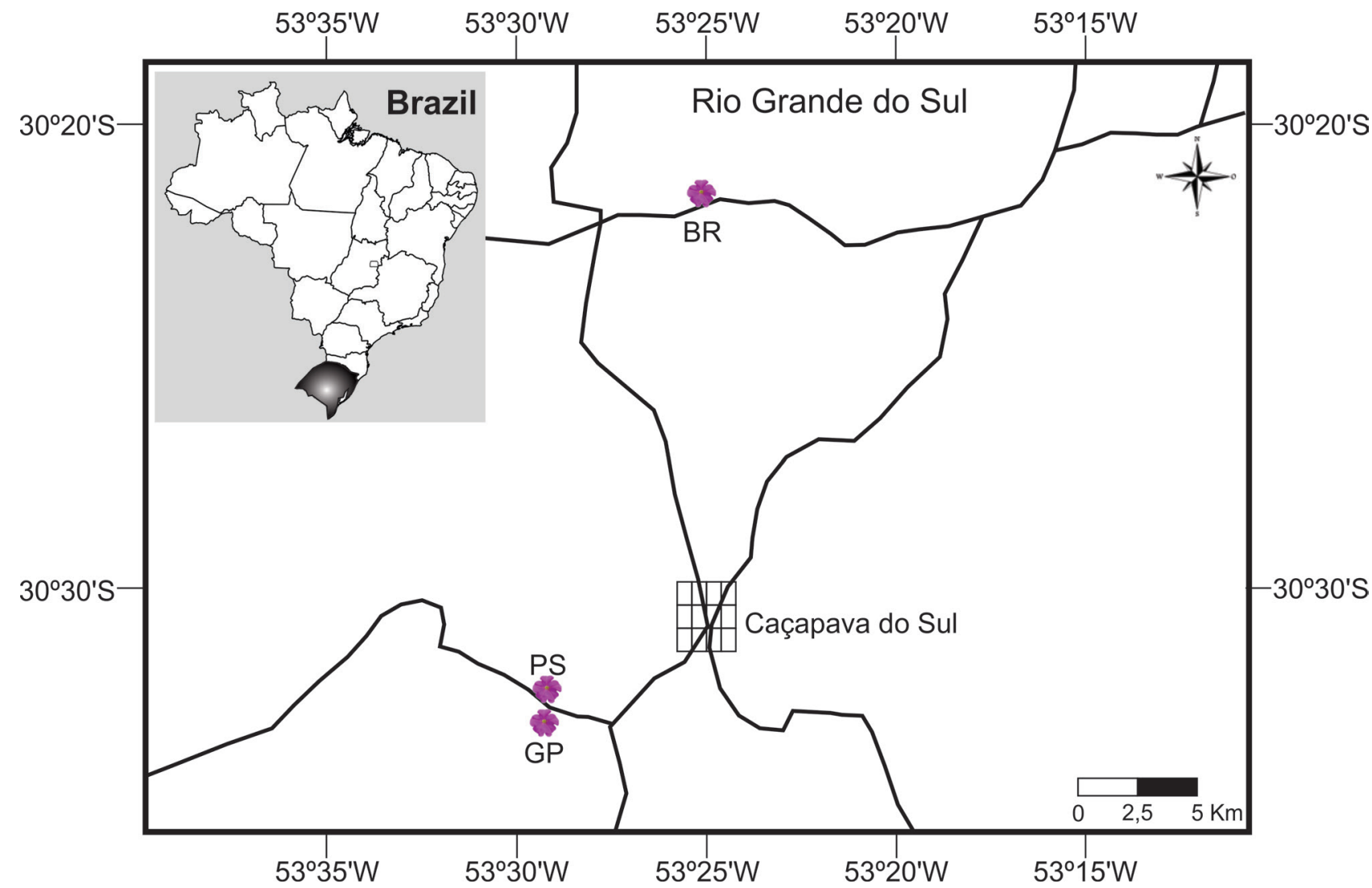

Figure 1. Geographical location and distribution of the studied populations of Petunia secreta in the municipality of Caçapava do Sul, Rio Grande do Sul, Brazil. 
all in a flat roadside area of open vegetation, ca. 20-30 $\mathrm{km}$ from Pedra do Segredo, in the adjacent municipality of Caçapava do Sul $\left(30^{\circ} 21^{\prime} \mathrm{S} 53^{\circ} 28^{\prime} \mathrm{W}\right)$. The habitat of the roadside population of $P$. secreta is similar to that of $P$. axillaris, although we did not observe these two species near each other.

To estimate the reproductive parameters in $P$. secreta, we sampled five populations (Tab. 1) at sites representing the species' main habitats (sandstone tower complex and roadside). These five populations were chosen to cover the larger area at the core of the native distribution of this species, as well as both evolutionary lineages (Turchetto et al. 2016). Within each of the two main sites, the distance between sampled populations ranged from around 0.2 $\mathrm{km}$ (BR163 and BR573) to $1.2 \mathrm{~km}$ (PS59 and GP62). The Pedra do Segredo and roadside assemblies are separated by around $20-30 \mathrm{~km}$. For the hand pollination experiments, we collected mature seeds from five individuals per population in nature during the flowering season of 2014 (September-December). The seeds were then germinated in a growth chamber at $22{ }^{\circ} \mathrm{C}$ in a 12 -h light:12-h dark cycle. To maximize germination, the seeds were pre-treated with a $100 \mu \mathrm{M}$ solution of gibberellic acid ( $\mathrm{GA}_{4}$; SigmaAldrich Co., St. Louis, MO, USA), dissolved in $1 \mathrm{~mL}$ DMSO (dimethyl sulfoxide; Sigma-Aldrich) and then diluted in water (Ali-Rachedi et al. 2004). Treatment was applied in a dark chamber at $4{ }^{\circ} \mathrm{C}$ for $24 \mathrm{~h}$. Germination began four days after planting, and the initial germination success was high ( $88.4 \pm 4.6 \%$, population mean $\pm S E$, $\mathrm{N}=150$ seeds in the first seven days). Eight seedlings per population were randomly chosen for transfer to a greenhouse, where they were cultivated until bloom in accordance with the standard practice for garden petunias, for a total of 40 plants.
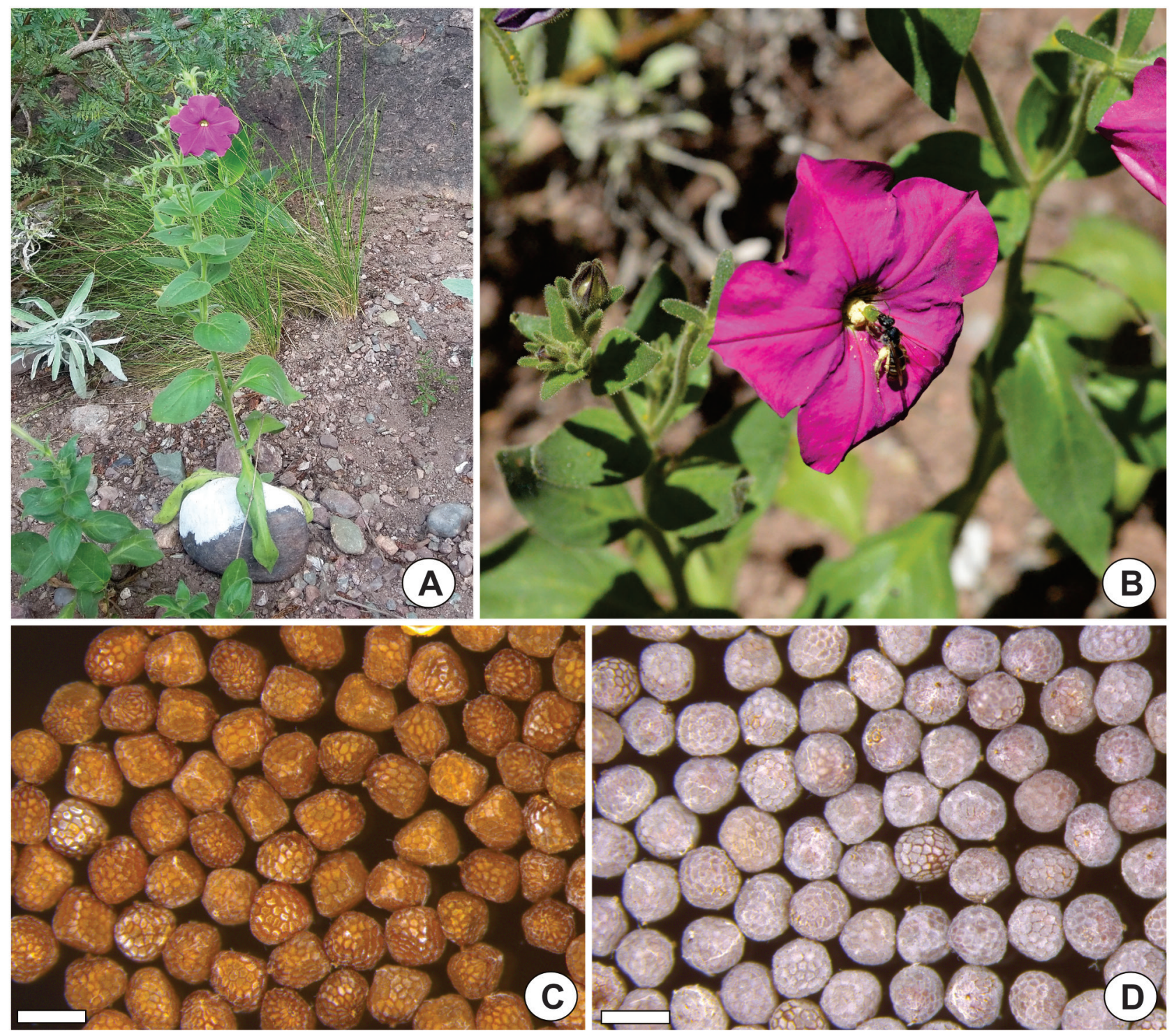

Figure 2. A. General view of the Petunia secreta plant. B. Pseudagapostemon sp. collecting pollen on Petunia secreta in Pedra do Segredo. C-D. Seeds of different colours under the stereomicroscope. Bars $=2 \mathrm{~mm}$. 
Table 1. Sampling information for plants collected in nature.

\begin{tabular}{|c|c|c|c|}
\hline Population & Location & Evolutionary lineage* & Coordinates \\
\hline PS59 & Pedra do Segredo & 1 & $30^{\circ} 32^{\prime} 09.56^{\prime \prime} S 53^{\circ} 33^{\prime} 06.82^{\prime \prime} \mathrm{W}$ \\
\hline GP62 & Pedra do Segredo & 1 & $30^{\circ} 32^{\prime} 45.90^{\prime \prime} \mathrm{S} 53^{\circ} 33^{\prime} 00.97^{\prime \prime} \mathrm{W}$ \\
\hline BR142 & Roadside & 2 & $30^{\circ} 21^{\prime} 32.79^{\prime \prime} \mathrm{S} 53^{\circ} 28^{\prime} 33.73^{\prime \prime} \mathrm{W}$ \\
\hline BR163 & Roadside & 2 & $30^{\circ} 21^{\prime} 30.80^{\prime \prime} \mathrm{S} 53^{\circ} 28^{\prime} 45.38^{\prime \prime} \mathrm{W}$ \\
\hline BR573 & Roadside & 2 & $30^{\circ} 21^{\prime} 31.70^{\prime \prime} \mathrm{S} 53^{\circ} 28^{\prime} 52.60^{\prime \prime} \mathrm{W}$ \\
\hline
\end{tabular}

*According Turchetto et al. (2016)

\section{Reproductive experiments}

To determine the reproductive system of $P$. secreta, five pollination treatments were applied in the greenhouse: (1) autonomous apomixis: buds were isolated in a mesh bag, and anthers were removed before dehiscence; (2) autonomous self-pollination: buds were bagged throughout their anthesis; (3) hand self-pollination: previously bagged flowers were hand pollinated with pollen from the same flower; (4) hand geitonogamy: bagged flowers were hand pollinated with pollen from a different flower from the same plant; (5) hand cross-pollination: bagged flowers were emasculated before anthesis and pollinated with pollen from plants obtained from other populations. For all experiments, bags were kept until fruit spontaneously opened. The number of fruits from each treatment was recorded after three weeks, and the fruit set was estimated as the proportion of flowers setting fruits. Mature fruits were collected and their seeds kept at $4^{\circ} \mathrm{C}$. Overall, we analysed 468 flowers across all plants, populations, and pollination treatments (Tab. 2). We also recorded several morphological characters of the plants, including flowers, fruits, and seeds, to characterise the two lineages of $P$. secreta.

\section{Seed production and germinability}

For each pollination treatment, we collected the seeds of three randomly selected fruits in a $0.2 \mu \mathrm{L}$ tube. The seeds were weighed, and their weight served as a representative estimate of seed production. Up to 100 randomly selected seeds per fruit were germinated in a growth chamber at $22^{\circ} \mathrm{C}$ in a 12 -h light: 12 -h dark cycle, as described previously. The total number of seeds was 6,500 . Upon emergence of the seedlings, the temperature was increased to $25^{\circ} \mathrm{C}$. Seedlings with open cotyledons were counted every seven days for seven weeks after planting. A comparison of germinability among seeds from different treatments and of different colours (see results) was carried out based on 200 randomly chosen seeds covering all colours and treatments.

\section{Data analysis}

Seedlings were observed until the cotyledons were fully open. Germinability was expressed as the cumulative percentage of seeds that had germinated by the end of the experiment. The statistical evaluation of seed germination data is not straightforward (McNair et al. 2012). Nevertheless, similar to a seed technology test, our intention here was to compare possible ways of crossing to provide an estimate of new plants potentially available in nature, and the chosen statistical tests are sufficient for this purpose (ISTA 1985). We used the Chi-square and Kruskal-Wallis tests implemented in the WinPEPI software suite (Abramson 2011) and the PASW/SPSS software to compare germinability across treatments and populations.

\section{Results}

\section{Vegetative growth and number and size of flowers}

During the initial developmental stages, plants from different populations and lineages presented identical vegetative morphology, with a rosette arrangement for all

Table 2. Reproductive success obtained per pollination treatment used in Petunia secreta.

\begin{tabular}{|c|c|c|c|c|c|c|c|c|c|c|c|c|c|c|c|}
\hline & \multicolumn{3}{|c|}{ PS59 } & \multicolumn{3}{|c|}{ GP62 } & \multicolumn{3}{|c|}{ BR142 } & \multicolumn{3}{|c|}{ BR163 } & \multicolumn{3}{|c|}{ BR573 } \\
\hline & n plant & n flower & $\mathrm{n}$ fruit & n plant & n flower & $\mathrm{n}$ fruit & n plant & n flower & $n$ fruit & n plant & n flower & $\mathrm{n}$ fruit & n plant & n flower & $n$ fruit \\
\hline $\begin{array}{l}\text { Autonomous } \\
\text { apomixes }\end{array}$ & 8 & 16 & 0 & 8 & 11 & 0 & 8 & 21 & 0 & 4 & 15 & 0 & 7 & 14 & 0 \\
\hline $\begin{array}{l}\text { Autonomous } \\
\text { self-pollination }\end{array}$ & 8 & 19 & 0 & 8 & 13 & 0 & 8 & 26 & 0 & 4 & 15 & 0 & 7 & 17 & 0 \\
\hline $\begin{array}{c}\text { Hand } \\
\text { self-pollination }\end{array}$ & 8 & 18 & 18 & 8 & 12 & 12 & 8 & 20 & 20 & 4 & 15 & 15 & 7 & 17 & 17 \\
\hline Hand geitonogamy & 8 & 15 & 15 & 8 & 9 & 9 & 8 & 15 & 15 & 4 & 14 & 14 & 7 & 16 & 16 \\
\hline $\begin{array}{l}\text { Hand cross- } \\
\text { pollination }\end{array}$ & 8 & 25 & 25 & 8 & 13 & 13 & 8 & 23 & 23 & 4 & 49 & 49 & 7 & 40 & 40 \\
\hline
\end{tabular}


leaves. Just before bloom, the rosette-type shoots elongated in plants from PS59 and GP62 populations, from the Pedra do Segredo site. In plants from BR142, BR163, and BR573 populations, from the roadside collection site, four or five lateral shoots emerged before the elongation of the central rosette-type shoot. Plants from lineage 2 hence seemed to have invested more in vegetative growth than plants from lineage 1 . Nevertheless, no differences in flower numbers and in numbers of individual plants producing more than 20 flowers during the flowering season were observed among populations or lineages. As observed in nature, all individuals were able to maintain flowers and fruits simultaneously. Plants survived in the greenhouse for eleven months.

\section{Timeline of flower opening and senescence and fruit production}

As observed in nature (DM Rodrigues unpub. res.), flowers of $P$. secreta opened during the daytime and remained open for four days if not pollinated. Senescence began around four days after flower aperture and was characterised by changes in the colour of the corolla, followed by the gradual wilting of the petals. In pollinated flowers, senescence started two days after pollination; otherwise, it resembled that of non-pollinated flowers. Anther dehiscence occurred simultaneously with the opening of the flower (within around 30 minutes), and the anthers were always positioned below the stigma. No differences were observed among plants or populations. In unfertilised flowers, the wilted corolla remained attached to the calix; in fertilised flowers, it fell as fruits were developing.

Among the five pollination treatments applied here, only autonomous apomixis and autonomous self-pollination did not produce any fruits (Tab. 2), indicating that P. secreta depends on a pollinator to set fruits, while being, at least partially, self-compatible.

\section{Seed quantity estimates}

In all plants, the fruit-stalk was erect and contained hundreds of seeds. No differences in estimated seed content were observed between pollination treatments that did produce fruit (Kruskal-Wallis test; $\mathrm{P}>0.05$ ). The weight of $0.2 \mathrm{~mL}$ of seeds (mean of three fruits $\pm \mathrm{SE}$ ) was: hand self-pollination, $0.193 \pm 0.01 \mathrm{~g}$; hand geitonogamy, 0.198 $\pm 0.01 \mathrm{~g}$; hand cross-pollination, $0.188 \pm 0.01 \mathrm{~g}$. The results for cross-pollination are based on crosses both within and between lineages.

\section{Seed germinability}

Considering all plants, populations, and treatments, the average rate of germinability was $73 \%$ (9\% to $100 \%$; Tab. 3). Pollination treatment germinability results differed between populations (data not shown) and between lineages (Fig. 3A). There were no marked differences in germinability between pollination treatments within lineage 2, whereas the highest germinability was observed after hand geitonogamy in lineage 1.

For hand self-pollination, hand geitonogamy, and hand cross-pollination within and between lineages, all tested flowers produced fruits full of seeds. The obtained seeds were of two different colours, brown and grey (Fig. 2C, D). These colours were observed for all modes of pollination, individuals, and populations, suggesting natural polymorphism. Seed colour proportions were similar for all treatments and ranged around $50 \%$. No correlation was observed between seed colour and germinability (KruskalWallis test; $\mathrm{P}>0.6$ ). Considering all pollination treatments and plants, a mean of $68 \%$ of seeds germinated for each colour, with a range of $0 \%$ to $100 \%$.

Germinability tests showed greater differences between plants and pollination treatments than fruit production. Each population presented a different pattern of germinability in relation to pollination treatments (Tab. 3). The only population that did not show differences in germinability between pollination treatments was BR573, where all capsules showed a similar mean of germinability (Tab. 3). In general, germinability indices were lower in plants from PS59 and GP62 (lineage 1) than in plants from BR142, BR163, and BR573 (lineage 2). The lowest values were observed for plants from GP62 that received pollen

Table 3. Seed germinability expressed as percentage ${ }^{1}$ of seedlings with open cotyledons per population per treatment in Petunia secreta considering eight plants per population.

\begin{tabular}{|c|c|c|c|c|c|c|c|c|c|c|c|c|c|c|c|}
\hline & \multicolumn{3}{|c|}{ PS59 } & \multicolumn{3}{|c|}{ GP62 } & \multicolumn{3}{|c|}{ BR142 } & \multicolumn{3}{|c|}{ BR163 } & \multicolumn{3}{|c|}{ BR573 } \\
\hline & Mean' & Min & Max & Mean & Min & $\operatorname{Max}$ & Mean & $\operatorname{Min}$ & $\operatorname{Max}$ & Mean & Min & $\operatorname{Max}$ & Mean & Min & Max \\
\hline Self $^{2}$ & 45 & 30 & 87 & 48 & 10 & 83 & 68 & 42 & 94 & 96 & 95 & 96 & 92 & 88 & 95 \\
\hline Geito $^{3}$ & 59 & 21 & 100 & 30 & 9 & 98 & 83 & 76 & 89 & 93 & 91 & 94 & 96 & 95 & 96 \\
\hline Out (within) ${ }^{4}$ & 36 & 9 & 100 & 9 & 9 & 10 & 87 & 78 & 93 & 95 & 92 & 98 & 95 & 93 & 97 \\
\hline Out (between) ${ }^{5}$ & 57 & 9 & 95 & 48 & 26 & 92 & 83 & 56 & 99 & 67 & 22 & 92 & 96 & 92 & 100 \\
\hline
\end{tabular}

$1 \%$ estimates were based on overall 6,500 seeds cultivated in growth chamber and controlled conditions during seven weeks; 2 hand pollination using pollen from the same flower; 3hand pollination using pollen from different flower from the same individual; 4 hand outcrossing using pollen from individuals from the same evolutionary lineage; 5hand outcrossing using pollen from individuals from different evolutionary lineage; Mean - considering at least 100 seeds per plant and eight plants per population; Min - minimum number of seedlings; Max - maximum number of seedlings. All differences were statistically significant, with $\mathrm{P}<0.001$. 
from PS59 (Fig. 3A). In plants from populations PS59, GP62, and BR142, capsules obtained from hand geitonogamy had higher seed germinability than those obtained through hand self-pollination (Fig. 3B, C). In plants from population BR142, no differences were observed between hand geitonogamy and hand outcrosses, independently of the pollen donor, whereas for plants from BR163, a lower germinability was observed for capsules resulting from outcrosses with plants from populations PS59 or GP62 (Fig. 3C). Independent of the mode of pollination, plants from PS59 had a higher germinability than plants from GP62 (Fig. 3B), whereas in lineage 2 (Fig. 3C), plants from BR142 had the lowest germinability (except when these plants received pollen from plants from lineage 1 ). All differences were statistically significant, with $\mathrm{P}<0.001$.

\section{Discussion}

We investigated the reproductive system of $P$. secreta through a range of hand pollination experiments. The geographic range of the species is fragmented, with small populations at Pedra do Segredo, and slightly larger populations at a roadside location $\sim 20 \mathrm{~km}$ from Pedra do Segredo. Our experiments showed that the species as a whole is self-compatible but non-autogamous, and there were no marked barriers for pollination between lineages and populations. The results are discussed in detail below.

According to Charlesworth (2006), it is useful to distinguish two types of plant reproductive systems, which can both contribute to our understanding of genetic diversity and population structure in plant species: (1) "sex systems", which consider whether the plant is monoecious, dioecious, or other, and (2) the mating systems of monoecious plants, including inbreeding, outcrossing, and intermediate mixed systems. Petunia secreta is a hermaphrodite plant, in which the stigma is located slightly above the anthers (Stehmann \& Semir 2005; Fig. 2B). No significant differences are found in morphology across populations (Turchetto et al. 2016). Additionally, P. secreta displays several characteristics to attract bees (DM Rodrigues unpubl. res.; Fig. 2B), suggesting that the species is dependent on a pollinator. Our results fully confirm this, as neither autonomous apomixis nor autonomous selfing led to the production of fruit.

Although dependent on pollinators, $P$. secreta does not seem to have any genetic mechanisms to prevent endogamy, since hand selfing and geitonogamy produced fruits in all studied populations. In addition, seed germinability was higher in several of these fruit than in fruit produced through other modes of pollination, suggesting that $P$. secreta is, at least in part, self-compatible (Figs. 2, 3). The loss of self-incompatibility and increase of endogamy have been seen in P. axillaris populations occurring in sympatry with P. exserta (Turchetto et al. 2015). Petunia secreta grows in the same area as P. axillaris and P. exserta, two species
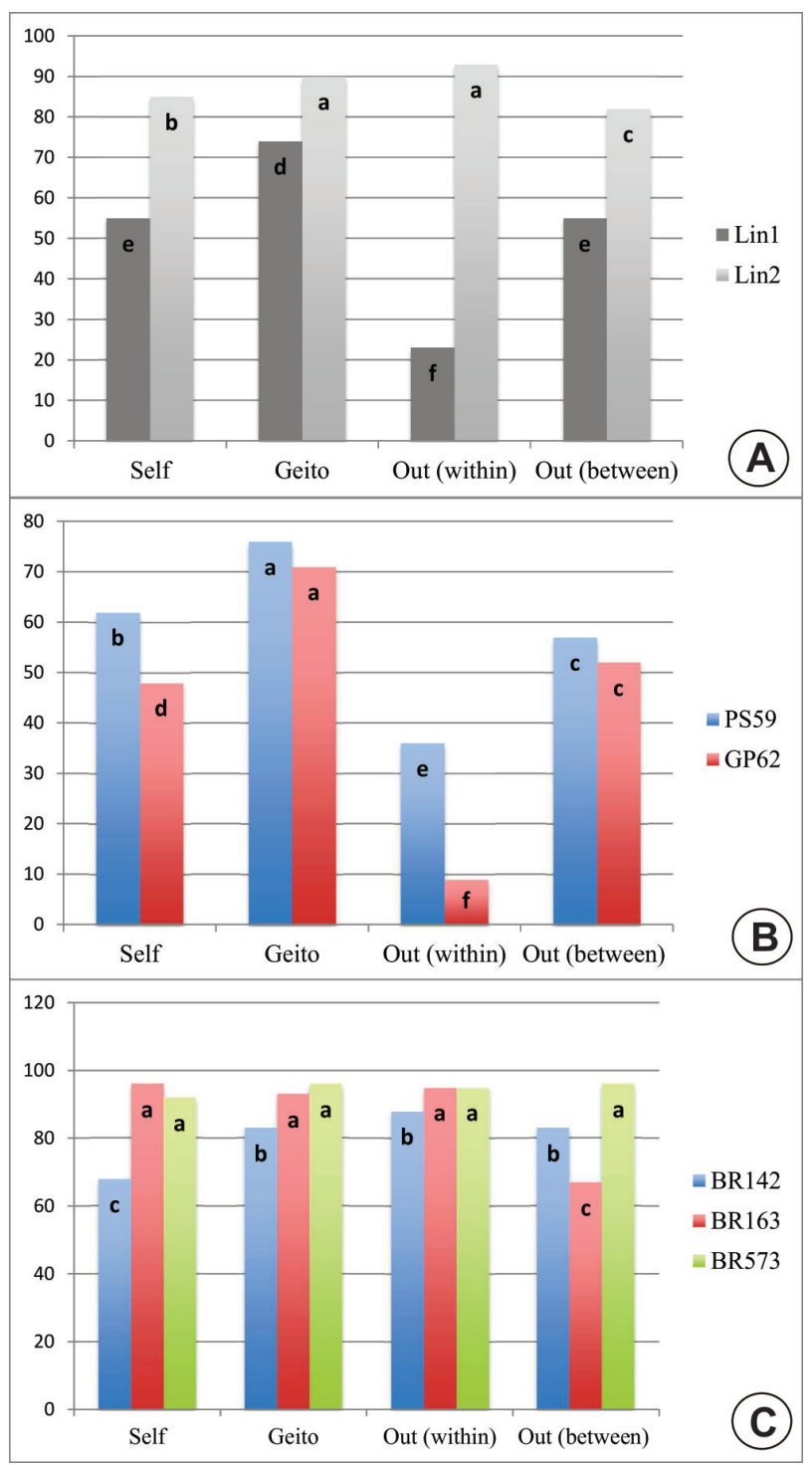

Figure 3. Comparison of the germinability after different pollination treatments in different populations and evolutionary lineages of Petunia secreta. A. Comparison between the two evolutionary lineages. B. Comparison between two populations from Pedra do Segredo locality (lineage 1). C. Comparison between three roadside populations (lineage 2). Different letters indicate statistical significance $(\mathrm{P}<0.001$; Kruskal-Wallis test). Seed germinability is shown on the vertical axis (mean of three experiments). Self-pollination - Self; Geitonogamy - Geito; Crosspollination within lineage or populations - Out within; or between lineages or populations - Out between.

that share a recent common ancestor with $P$. secreta (ReckKortmann et al. 2014), and as P. integrifolia, which is also bee-pollinated.

Reproductive success in stressful or variable environments, in which pollination may be uncertain, is a common problem for many lineages of seed plants. For outcrossing species in disturbed habitats, pollinator limitation and restricted partner availability are commonly encountered problems (Yin et al. 2016). Petunia secreta has a 
fragmented distribution across disturbed areas, where plants are generally found in small populations (Turchetto et al. 2016). While these attributes generally suggest a depletion of genetic diversity (Ellstrand \& Elam 1993), they are not reliable predictors of genetic dynamics (Premoli et al. 2001), as is demonstrated by our findings in $P$. secreta. The rate of seed germinability in endogamous treatments was at least equivalent to that obtained from outcrossing (Fig. 3), suggesting a high tolerance of endogamy in this species. This seems to enable $P$. secreta to overcome the limitations in partner availability and to keep high genetic diversity indices despite the potentially low level of long distance gene flow as a consequence of the distance between individuals.

In this study we observed that non-pollinated $P$. secreta flowers remained open and fresh and kept a receptive stigma over four days, while pollinated flowers entered senescence two days earlier. These findings parallel observations of nonpollinated flowers in nature (DM Rodrigues unpubl. res.).

Plant species have evolved a range of reproductive strategies to cope with unfavourable pollination conditions. For example, plants faced with severe pollinator restriction, and hence reduced possibilities for cross-pollination, can ensure reproductive success by increasing self-compatibility (Larson \& Barrett 2000). In P. secreta, both hand selfing and geitonogamy resulted in high levels of seed germinability (Tab. 3).

Likewise, prolonged floral longevity can compensate for a low rate of pollinator visitation (Barrett 2003) and can be seen as an evolutionary strategy to overcome a sparse or unpredictable pollinator service (Steinacher \& Wagner 2010). In line with this, Darling \& Barrett (2011) showed that flowers with longer exposure times had greater chances to be visited by pollinators, as well as a higher reproductive success. Unpredictability in the availability of pollinators or partners can lead to selection for a combination of self-compatibility and improved outcrossing pollination strategies (Kalisz et al. 2004). This seems to be the case in $P$. secreta, since the differences in germinability were greater between populations than between pollination treatments (Figs. 2, 3).

In small populations, several evolutionary processes, including genetic drift, can lead to a reduction in genetic variation and increase the rate of endogamy with all its negative consequences. Mechanisms preventing selffertilization might act in very small populations to avoid genetic load and inbreeding depression. In line with this, an increase in the proportion of heterozygotes has been observed in sexual species (Cole 2003). When a species is divided into a series of small populations, which are so isolated from each other that dispersal rarely carries genes from one population to another, genetic drift can lead to divergent allele frequencies in the isolated populations, increasing the levels of several diversity indicators (Ellstrand 1992). As previously shown through the analysis of microsatellites (Turchetto et al. 2016), $F_{S T}$ values are higher in P. secreta lineages $\left(F_{S T}=0.358\right)$ than in other Petunia species with larger geographic distribution and/or bigger populations ( $P$. secreta and $P$. exserta $-F_{S T}=0.195 ;$. secreta and $P$. axillaris $-F_{S T}=0.080 ;$ P. axillaris and $P$. exserta $-F_{S T}=$ $0.113)$. Thus, endogamy, coupled with occasional gene flow due to pollen or seed dispersal between populations, could satisfactorily explain the genetic structure found in P. secreta.

The high levels of genetic diversity and population scattering in $P$. secreta may be better explained by the species' herkogamic flowers than by the action of a molecular self-incompatibility mechanism (see the results for hand self-pollination, Fig. 3). Herkogamy has been described to affect selfing and outcrossing proportions (Palma-Silva et al. 2015; Neri et al. 2017) and may contribute to maintain genetic diversity levels within populations by reinforcing outcrossing strategies to face potential endogamy.

Various factors affecting the reproductive system, including the mode of pollination, pollinator viability, and the presence of molecular or structural self-incompatibility systems (Karron et al. 2012), might contribute to an explanation of our findings. Moreover, when pollinators move only over short distances, as in the case of the solitary bees found to visit $P$. secreta (DM Rodrigues unpubl. res.; Fig. 2B), and when pollen carryover is limited, as it might happen in the small populations of $P$. secreta (Turchetto et al. 2016), a large fraction of the pollen deposited on a stigma might come from closely related individuals (Mitchell et al. 2009). Alternatively, it might constitute a mix of selfpollen, pollen of relatives, and pollen from distant donors. If all pollen, independent of its origin, has the same ability to fertilize and develop viable seeds, as we observed here for all pollination treatments (Figs. 2, 3), high diversity levels would be obtained, both for the population and for the species in general.

Clearly, the genetic dynamics of a species should not be predicted based on its geographical range alone: widely distributed species are not always characterised by high levels of genetic diversity (Paggi et al. 2015); conversely, genetic diversity levels are not necessarily low in species with a narrow distribution (Fernández-Mazuecos et al. 2014; Jiménez-Mejías et al. 2015; Forrest et al. 2017). A great number of factors can influence diversity levels within and between populations. These include the nature of the reproductive system (Coppi et al. 2014), which affects several aspects of the natural biology of plants, such as population homozygosity and genetic variability, as well as large effective population sizes, a common explanation for the maintenance of diversity in rare species (Ellstrand \& Elam 1993) such as P. secreta.

Based on the present results and on the genetic microsatellite variability described in a previous paper (Turchetto et al. 2016), we conclude that the reproductive systems in place in $P$. secreta, coupled with a large ancestral effective population size, may be responsible for the high diversity observed in this species. We observed that $P$. secreta 
does not show autonomous self-pollination and, although we do not know the rates of cross-pollination in nature, the elevated levels of homozygosity observed previously (Turchetto et al. 2016) suggest that $P$. secreta might show some degree of inbreeding. We conclude that the greatest risk to the species lies in the small and fragmented nature of its populations, highlighting the importance of including $P$. secreta in the Brazilian red list of plant species.

\section{Acknowledgements}

We thank G. Mäder and A.L.A. Segatto for help with the fieldwork, and B. Kremeyer for help with proof reading. Financial Support: Conselho Nacional de Desenvolvimento Científico e Tecnológico (CNPq), Coordenação de Aperfeiçoamento de Pessoal de Nível Superior (CAPES), Fundação Grupo O Boticário de Proteção à Natureza, and Programa de Pós-Graduação em Botânica da Universidade Federal do Rio Grande do Sul (PPGBot-UFRGS). C.T. was supported by PNPD-CAPES/PPGBM, UFRGS. This study was conducted under the permission number 41530-5 MMA/ICMBio/SISBIO.

\section{References}

Abramson JH. 2011. WINPEPI updated: computer programs for epidemiologists, and their teaching potential. Epidemiologic Perspectives \& Innovations 8: 1.

Aguilar R, Quesada M, Ashworth L, Herrerias-Diego Y, Lobo J. 2008 Genetic consequences of habitat fragmentation in plant populations: susceptible signals in plant traits and methodological approaches. Molecular Ecology 17: 5177-5188.

Ali-Rachedi S, Bouinot D, Wagner M, et al. 2004. Changes in endogenous abscisic acid levels during dormancy release and maintenance of mature seeds: studies with Cape Verde Islands ecotype, the dormant model of Arabidopsis thaliana. Planta 219: 479-488.

Barrett SCH. 2003. Mating strategies in flowering plants: The outcrossingselfing paradigm and beyond. Philosophical Transactions of the Royal Society B 358: 991-1004.

Blambert L, Mallet B, Humeau L, Pailler T. 2016. Reproductive patterns, genetic diversity and in-mating depression in two closely related Jumellea species with contrasting patterns of commonness and distribution. Annals of Botany 118: 93-103.

Charlesworth D. 2006. Evolution of plant breeding systems. Current Biology 16: R726-R735.

Cole CT. 2003. Genetic variation in rare and common plants. Annual Review in Ecology, Evolution and Systematics 34: 231-237.

Coppi A, Cecchi L, Mengoni A, Pustahija F, Tomovic G, Selvi F. 2014. Low genetic diversity and contrasting patterns of differentiation in the two monotypic genera Halacsya and Paramoltkia (Boraginaceae) endemic to the Balkan serpentines. Flora 209: 5-14.

Darling ES, Barrett SCH. 2011. Sit-and-wait pollination in the spring flowering woodland plant, Trillium grandiflorum. Journal of Pollination Ecology 5: 81-85.

Ellstrand NC. 1992. Gene flow by pollen: implications for plant conservation genetics. Oikos 63: 77-86.

Ellstrand NC, Elam DR. 1993. Population genetic consequences of small population size: implications for plant conservation. Annual Review of Ecology and Systematics 24: 217-242.

Fernández-Mazuecos M, Jiménez-Mejías P, Rotllan-Puig X, Vargas P. 2014. Narrow endemics to Mediterranean islands: moderate genetic diversity but narrow climatic niche of the ancient, critically endangered
Naufraga (Apiaceae). Perspectives in Plant Ecology, Evolution and Systematics 16: 190-202.

Forrest A, Escudero M, Heuertz M, Wilson Y, Cano E, Vargas P. 2017. Testing the hypothesis of low genetic diversity and population structure in narrow endemic species: the endangered Antirrhinum charidemi (Plantaginaceae). Botanical Journal of the Linnean Society 183: 260-270.

Ghazoul J. 2005. Pollen and seed dispersal among dispersed plants. Biological Reviews 80: 413-443.

ISTA - International Seed Testing Association. 1985. International rules for seed testing. Seed Science and Technology 13: 307-513.

Jiménez-Mejías P, Fernández-Mazuecos M, Amat ME, Vargas P. 2015. Narrow endemics in European mountains: high genetic diversity within the monospecific genus Pseudomisopates (Plantaginaceae) despite isolation since the late Pleistocene. Journal of Biogeography 42: 1455-1468.

Kalisz S, Vogler DW, Hanley KM. 2004. Context-dependent autonomous self-fertilization yields reproductive assurance and mixed mating. Nature 430: 884-887.

Karron JD, Ivey CT, Mitchell RJ, Whitehead MR, Peakall R, Case AL. 2012. New perspectives on the evolution of plant mating systems. Annals of Botany 109: 493-503.

Larson BMH, Barrett SCH. 2000. A comparative analysis of pollen limitation in flowering plants. Biological Journal of the Linnean Society 69: 503-520.

McNair JN, Sunkara A, Frobish D. 2012. How to analyse seed germination data using statistical time-to-event analysis: non-parametric and semi-parametric methods. Seed Science Research 22: 77-95.

Mitchell RJ, Flanagan RJ, Brown BJ, Waser NM, Karron JD. 2009. New frontiers in competition for pollination. Annals of Botany 103: 14031413.

Neri J, Leles BP, Wendt T, Palma-Silva C. 2017. Variation in reproductive system facilitates species boundaries of sympatric Vriesea (Bromeliaceae). Botanical Journal of the Linnean Society 184: 272-279.

Paggi GM, Palma-Silva C, Zanettini MHB, Lexer C, Bered F. 2015. Limited pollen flow and high selfing rates towards geographic range limit in an Atlantic forest bromeliad. Flora 211: 1-10.

Palma-Silva C, Cozzolino S, Paggi GM, Lexer C, Wendt T. 2015. Mating system variation and assortative mating of sympatric Bromeliads (Pitcairnia spp.) endemic to Neotropical inselbergs. American Journal of Botany 102: 1-7.

Premoli AC, Souto CP, Allnutt TR, Newton AC. 2001. Effects of population disjunction on isozyme variation in the widespread Pilgerodendron uviferum. Heredity 87: 337-343.

RADAMBRASIL Project. 2013. RADAMBRASIL para Download. https:// sosgisbr.com/2013/11/13/radambrasil-para-download/

Reck-Kortmann M, Silva-Arias GA, Segatto ALA, Mäder G, Bonatto SL, Freitas LB. 2014. Multilocus phylogeny reconstruction: new insights into the evolutionary history of the genus Petunia. Molecular Phylogenetics and Evolution 81: 19-28.

Stehmann JR, Semir J. 2005. New species of Calibrachoa and Petunia (Solanaceae) from subtropical South America. Monographs in Systematic Botany 104: 341.

Stehmann JR, Lorenz-Lemke AP, Freitas LB, Semir J. 2009. The genus Petunia. In: Gerats T, Strommer J. (eds.) Petunia evolutionary, developmental and physiological genetics. New York, Springer. p. 1-28.

Steinacher G, Wagner J. 2010. Flower longevity and duration of pistil receptivity in high mountain plants. Flora 205: 376-387.

Turchetto C, Lima JS, Rodrigues DM, Bonatto SL, Freitas LB. 2015. Pollen dispersal and breeding structure in a hawkmoth-pollinated Pampa grasslands species Petunia axillaris (Solanaceae). Annals of Botany 115: 939-948.

Turchetto C, Segatto ALA, Mäder G, Rodrigues DM, Bonatto SL, Freitas LB. 2016. High levels of genetic diversity and population structure in an endemic and rare species: Implications for conservation. AoB Plants 8: plw002. doi: 10.1093/aobpla/plw002.

Yin G, Barrett SCH, Luo Y-B, Bai W-N. 2016. Seasonal variation in the mating system of a selfing annual with large floral displays. Annals of Botany 117: 391-400. 